\title{
Renoprotective Effects of Valsartan And Amlodipine in a Nephrotoxic Model of Experimental Animals
}

\author{
Doa'a Anwar Ibrahim*, Ahmed Al-mohamady \\ Clinical Pharmacy and Pharmacy Practice, Department- Faculty of Pharmacy-UST, Sana'a, YEMEN.
}

\begin{abstract}
Background: Calcium channel blockers and AT1 antagonists have efficacious effects to control elevated blood pressure by different mechanisms. They are used widely in co-morbid hypertensive patients either to prevent deterioration of blood pressure or to protect the cardiovascular diseases from further progression. Objectives: This work aims to investigate the protective effects of valsartan and amlodipine against gentamicin-induced nephrotoxicity in experimental animals. Methods: Twenty-four rabbits were divided randomly into four groups, each of six animals. The first group was kept as the normal control group. Second, third and fourth groups were taken as a nephrotoxic model by giving gentamicin $(80 \mathrm{mg} / \mathrm{kg}$ IP) for 7 days. Blood samples were collected to investigate the kidney biomarkers including serum creatinine, BUN, Crcl, uric acid and potassium level. Urine collection was done to measure $\mathrm{pH}$, volume as well as urine creatinine. Bodyweight was measured before and after treatment, furthermore, the weights of heart and kidneys were done at the end of the study. Results: The outcomes of this study showed a significant elevation in all kidney biomarkers in a nephrotoxic-induced group accompanied by the reduction
\end{abstract}

in the weights of heart and kidney as compared with the control one. The treated groups either valsartan or amlodipine showed little improvements in some parameters compared with the nephrotoxic-induced group. Conclusion: From the results of the present study, it was suggested that both medications might have renoprotective effects that obviously reduced the kidney biomarkers as well as there was no significant difference between the two drugs concerning their protective effect.

Key words: Renoprotective effects, Valsartan, Amlodipine, Nephrotoxic Model, Experimental Animals.

Correspondence

Prof. Doa'a Anwar Ibrahim, Professor of Pharmacology, Clinical Pharmacy and Pharmacy Practice Department- Faculty of Pharmacy-UST, Sana'a, YEMEN.

Phone: +967-733308292

Email: dr_d_anwar@hotmail.com;

ORCID: http://orcid.org/0000-0002-3729-5303

DOI: 10.5530/ijpi.2020.2.38

\section{INTRODUCTION}

Nephrotoxicity is defined as an abnormal renal function that may be resulted from using some drugs like analgesics, antidepressants, aminoglycosides, lithium and other medication. The effect of these medications may vary from acute or chronic interstitial nephritis, rhabdomyolysis, Tubular cell toxicity as well as glomerulonephritis. ${ }^{1,2}$ Gentamicin is one member of aminoglycoside antibiotics that causes nephrotoxicity and used in many studies as a nephrotoxic model agent..$^{3-5}$ The toxic effects are centered on the proximal convoluted tubules cells, which show many pathological changes including the generalized formation of numerous lysosomal cytosegresomes and myeloid bodies, together with focal cellular necrosis. ${ }^{6}$ However, valsartan is a novel and orally potent angiotensin AT1-receptor blockers (ARB) that dose-dependent lowering blood pressure sold either alone or in combination with other antihypertensive agents. It is soluble in the neutral $\mathrm{pH}$ range. It classified as low permeability and high solubility drug. Valsartan is soluble in acetonitrile and methanol. The drug is rapidly absorbed orally and has a low volume of distribution with extensive bound to plasma proteins. non-renal routes mainly excrete Valsartan. Valsartan is effective in the treatment of patients with mild to moderate hypertension. ${ }^{7}$ It was found that valsartan has a renoprotective effect particularly in the diabetic patient with nephropathy in terms of reducing albuminuria. ${ }^{8}$ Additionally, amlodipine is a calcium channel blocker member that inhibits calcium ion influx across cell membranes selectively. It belongs to dihydropyridine derivatives that have more vascular selectivity and beneficial vasodilation with a low negative inotropic effect. ${ }^{9}$ After an oral administration of therapeutic doses, absorption produces peak plasma concentrations between 6 and $12 \mathrm{hr}$. It is extensively converted to inactive metabolites via hepatic metabolism, and its elimination from the plasma is biphasic with a terminal elimination half-life of about 30-50 hours. ${ }^{10}$ This study aims to investigate the renoprotective effects of two famous antihypertensive drugs valsartan and amlodipine in the nephrotoxic animal model.

\section{METHODS}

\section{Drugs}

Amlodipine supplied as tablets each contains $5 \mathrm{mg}$ amlodipine besylate, valsartan, and Gentamicin sulfate was purchased from Alpha Aleppo Pharmaceutical Ind. Respectively.

\section{Experimental animals}

Twenty-four male New Zealand White Rabbits with a weight range from 1.5-1.8 kg were supplied from the Department of Biology-Sana'a University. They were left to acclimatize for one week with free accesses of water and fresh green grass and housed in stainless steel cages $\left(2500 \mathrm{~cm}^{2}\right.$ with a height of $35 \mathrm{~cm}$ ) away from direct sunlight. The approval of the University Ethical Committee was obtained before the experiment commencing [EAC/UST185].

\section{Study design}

Rabbits were divided randomly into four groups, each of six animals. The first group was kept as the normal control group. Second, third and 
fourth groups were kept as a nephrotoxic model by giving gentamicin (80mg/kg IP) for 7 days. ${ }^{11}$ Third and fourth groups were treated daily at $8-10$ a.m. for 7 days with valsartan $(10 \mathrm{mg} / \mathrm{kg} / \mathrm{d})$ and amlodipine $(5 \mathrm{mg} / \mathrm{kg} / \mathrm{d})$ by oral gavage procedure.

According to the 24 hours urine volume, urinary creatinine and serum creatinine concentration, creatinine clearance was calculated by applying the following formula: ${ }^{12}$

Creatine clearance $(\mathrm{ml} / \mathrm{min} /$ day $)=\frac{\mathrm{mg} \text { creatine } / \mathrm{dl} \text { urine } \times \mathrm{ml} \text { urine } 24 \mathrm{hr}}{\mathrm{mg} \text { creatinine } / \mathrm{dl} \text { serum } \times 400}$

At day 8, that was the end of the duration of the study, the animals were sacrificed by decapitation using light anesthesia with diethyl ether inhalation in anesthetic desiccator following the International animal guideline. After the maintenance anesthesia and the animals became calm, the blood samples were collected from the heart of rabbits to investigate the kidney biomarkers including serum creatinine, BUN, $\mathrm{Crcl}$, uric acid, and potassium level. Urine collection was done to measure $\mathrm{pH}$, volume as well as urine creatinine. Bodyweight was measured before and after treatment, furthermore, the weights of the heart and kidneys were done at the end of the study.

\section{RESULTS}

The urine parameters particularly urine $\mathrm{pH}$ and urine creatinine were elevated significantly in the nephrotoxic-induced group compared with the control group when given for 7 days as shown in Table 1 of the present study outcomes. Contradictory, the urine volume was significantly reduced in the nephrotoxic-induced group compared with the control group. Valsartan showed significant improvement in the urine volume compared with the nephrotoxic-induce group.

Concerning the kidney's biomarkers were elevated significantly in the nephrotoxic-induced group compared with the control group. Treated groups showed significant improvement especially in creatinine clearance compared with the nephrotoxic-induced group as shown in Table 2.

Additionally, the weights of the organs as heart and kidneys were reduced in the nephrotoxic-induced group compared with the control and treated groups but statistically insignificant. Bodyweight showed no change before and after given gentamicin or compared with control. Valsartan and amlodipine treated groups showed a significant reduction in body weight, as shown in Table 3.
Table 1: Effect of valsartan and amlodipine on (mean $\pm \mathrm{SE}$ ) kidney biomarkers in experimental animals $(n=6)$ for 8 days.

\begin{tabular}{ccccc}
\hline Parameters & Control & Gentamicin & Valsartan & Amlodipine \\
\hline Urine $\mathrm{pH}$ & $8.14 \pm 0.04$ & $10.13 \pm 0.099 \mathrm{a}$ & $8.97 \pm 0.14 \mathrm{~b}$ & $8.79 \pm 0.134 \mathrm{~b}$ \\
P-value & & 0.031 & 0.001 & 0.001 \\
Urine volume & $56.0 \pm 0.187$ & $24.0 \pm 3.94 \mathrm{a}$ & $43.6 \pm 2.87 \mathrm{~b}$ & $31.8 \pm 6.94$ \\
$(\mathrm{ml})$ & & 0.001 & 0.004 & 0.33 \\
P-value & & & & \\
U. creatinine & $16.39 \pm 5.33$ & $44.8 \pm 14.1 \mathrm{a}$ & $44.5 \pm 5.3$ & $42.1 \pm 17.0$ \\
P-value & & 0.03 & 0.99 & 0.89 \\
\hline
\end{tabular}

a significant as compared with control at $p<0.05$, b significant as compared with gentamicin-induced nephrotoxicity at $p<0.05$

Table 2: Effect of valsartan and amlodipine on (mean \pm SE) kidney biomarkers in experimental animals $(n=6)$ for 8 days.

\begin{tabular}{ccccc}
\hline Parameters & Control & Gentamicin & Valsartan & Amlodipine \\
\hline S. creatinin(mg/dl) & $1.03 \pm .08$ & $1.48 \pm 0.31 \mathrm{a}$ & $1.49 \pm 0.50$ & $1.29 \pm 0.20$ \\
P-value & & 0.033 & 0.105 & 0.283 \\
BUN(mg/dl) & $22.8 \pm 1.35$ & $48.3 \pm 16.3 \mathrm{a}$ & $31.0 \pm 4.37$ & $41.2 \pm 17.3$ \\
P-value & & 0.04 & 0.88 & 0.74 \\
CrCl (ml/min) & $0.81 \pm 0.26$ & $1.78 \pm 0.28 \mathrm{a}$ & $0.79 \pm 0.17 \mathrm{~b}$ & $0.82 \pm 0.25 \mathrm{~b}$ \\
P-value & & 0.04 & 0.02 & 0.03 \\
Uric acid(mmol/L) & $0.383 \pm .087$ & $0.216 \pm .030 \mathrm{a}$ & $0.440 \pm .315 \mathrm{~b}$ & $0.425 \pm .143 \mathrm{~b}$ \\
P-value & & 0.003 & 0.029 & 0.013 \\
$\mathrm{~K}+$ (mEq/L) & $4.25 \pm .0 .232$ & $3.966 \pm .095$ & $5.24 \pm .566 \mathrm{~b}$ & $4.92 \pm 0.396$ \\
$P$-value & & 0.27 & 0.002 & 0.12 \\
\hline
\end{tabular}

a significant as compared with control at $p<0.05$, b significant as compared with gentamicin-induced nephrotoxicity at $p<0.05$

\section{DISCUSSION}

Calcium channel blockers and angiotensin AT1 receptor blockers are the most efficacious antihypertensive groups that have satisfaction effects as renoprotective agents for patients suffering from kidney disease. ${ }^{13}$ Outcomes of the current study showed that gentamicin induced nephrotoxicity significantly through elevation of the kidney biomarkers including BUN, serum creatinine and creatinine clearance compared with the control group. Gentamicin is one member of aminoglycoside antibiotics and the nephrotoxic side effect is the major limitation of the therapeutic

Table 3: Effect of valsartan and amlodipine on (mean \pm SE) body weight, heart and kidney weights in experimental animals $(n=6)$ for 8 days.

\begin{tabular}{|c|c|c|c|c|c|c|c|c|}
\hline \multirow[t]{2}{*}{ Parameters } & \multicolumn{2}{|c|}{ Control } & \multicolumn{2}{|c|}{ Gentamicin } & \multicolumn{2}{|c|}{ Valsartan } & \multicolumn{2}{|c|}{ Amlodipine } \\
\hline & Before & After & Before & After & Before & After & Before & After \\
\hline Body weight (kg) & $1.6 \pm 0.10$ & $1.81 \pm 0.09$ & $1.69 \pm 0.07$ & $1.49 \pm 0.09$ & $1.74 \pm 1.54$ & $1.61 \pm 0.75 c$ & $1.75 \pm 0.03$ & $1.63 \pm 0.04$ \\
\hline \multirow[t]{2}{*}{ p-value } & & $0.04 \mathrm{c}$ & & $0.02 \mathrm{a}$ & 0.35 & 0.04 & & 0.1 \\
\hline & & & & & & 0.07 & & $0.04 \mathrm{~b}$ \\
\hline Weight of the heart (g) & - & $6.0 \pm 0.57$ & - & $4.0 \pm 0.58$ & - & $5.1 \pm 0.72$ & - & $5.2 \pm 0.44$ \\
\hline \multirow[t]{2}{*}{ The relative weight of the Heart } & - & 0.3 & - & 0.25 & - & 0.32 & - & 0.31 \\
\hline & & & & $0.04 \mathrm{a}$ & & & & \\
\hline \multirow[t]{2}{*}{ Weight of kidneys (g) } & - & $11.6 \pm 1.2$ & - & $8.0 \pm 0.57$ & - & $10.3 \pm 0.88$ & - & $9.3 \pm 1.2$ \\
\hline & & & & $0.03 \mathrm{a}$ & & & & \\
\hline The relative weight of the kidneys & - & 0.58 & - & 0.60 & - & 0.63 & - & 0.57 \\
\hline
\end{tabular}

(a) Significant as compared with control (before) at $p<0.05$, (b) significant as compared with gentamicin-induced nephrotoxicity at $p<0.05$, (c) significant compared with initial weight at $p<0.05$ 
use especially for gentamicin. ${ }^{14}$ This referred to the alkaline $\mathrm{pH}$ of gentamicin according to the pharmacokinetics of this medication, which also showed in the present work. ${ }^{15}$ It causes a deleterious effect on the kidney especially for those proximal tubules cells due to long persisting in the tubules which cause may direct injury or indirectly through the difference in osmolality. ${ }^{16}$ This effect has explained the reduction in the weight of the kidney as well as in the urine volume in the gentamicin group compared with the control group..$^{17}$ Abdelrahman, 2018 agreed with this finding as he found that gentamicin when used for one week it ended with a significant reduction in total body weight and increase in the renal somatic index (RSI) ${ }^{18}$

Amlodipine is a one member of calcium channel blockers (CCBs) that exerts its antihypertensive action through inhibiting calcium ion influx across cell membranes selectively, with a greater effect on vascular smooth muscle cells than on cardiac muscle cells. ${ }^{19}$ Additionally, valsartan inhibits Angiotensin II Receptor Type 1 selectively, which reduces elevated blood pressure. ${ }^{20}$ It was found there was a disparate pattern of intrarenal hemodynamics with the calcium channel blocker that amlodipine increased GFR (hyperinfiltration) compared with valsartan that maintain GFR at a constant level as well as an increase infiltration fraction in a study conducted on participants for 4 weeks. ${ }^{21}$ Additionally, another study conducted by Gjorgjievska et al. 2014 found that amlodipine showed a beneficial effect in reducing blood pressure in salt loaded rats but the effects on renal parameters mostly proteinuria were more evident in the group of animals treated with valsartan. Since both treatment groups have a different mechanism of action, combination therapy may be beneficial in improving renal function in spontaneously hypertensive rats 9 . All these findings agreed with the outcomes of the present study as it found both investigated medications ameliorated gentamicin-induced nephrotoxicity through improving the elevation of kidney biomarkers especially BUN and creatinine clearance with pronounced improvement effect of valsartan on urine volume than amoldipine.

\section{Limitations and strengths}

This is the first study conducted on the two widely used as first-line regimen antihypertensive agents around the world and compared between them regarding their protective effect on the renal system by measuring different related parameters. The histopathology of the kidney should be considered in the future study, as it did not carry out in this work.

\section{CONCLUSION}

From the outcomes of the present, study it suggested that both mediations might have protective effects against gentamicin-induced nephrotoxicity. They improve some kidney biomarkers as well as bodyweight additionally they improve the reduction of the heart and kidneys caused by gentamicin. All these findings interpret the clinical use of these medications in comorbid hypertensive patients.

\section{ACKNOWLEDGEMENT}

The authors would like to thank the faculty of Pharmacy and UST hospital lab for their valuable support.

\section{CONFLICT OF INTEREST}

The authors declare that they have no conflicts of interest

\section{ABBREVIATIONS}

ARB: angiotensin AT1-receptor blockers, CCBs: calcium channel blockers, BUN: blood urea nitrogen, Crcl: creatinine clearance, UST: University of Science and Technology.

\section{REFERENCES}

1. Naughton C. Drug-Induced Nephrotoxicity. AmFam Physician. 2008;78(6):743-50.

2. Perazella M. Renal vulnerability to drug toxicity. Clin J Am Soc Nephrol. 2009;4(7):1275-83.

3. Ghaznavi H, Fatemi I, Kalantari H, Tabatabaei S, Mehrabani M, Gholamine B, et al. Ameliorative effects of gallic acid on gentamicin-induced nephrotoxicity in rats. J Asian Nat Prod Res. 2018;20(12):1182-93.

4. Medic B, Stojanovic M, Rovcanin B, Kekic D, Škodric SR, Jovanovic GB, et al. Pioglitazone attenuates kidney injury in an experimental model of gentamicininduced nephrotoxicity in rats. Sci Rep. 2019;9(1):1.

5. Dursun M, Sahin S, Besiroglu H, Otunctemur A, Ozbek E, Cakir SS, et al. Protective effect of nebivolol on gentamicin-induced nephrotoxicity in rats. Bratisl Lek Listy. 2018;119(11):718-25.

6. Whiting HP, Petersen J, Simpson JG. Gentamicin-induced nephrotoxicity in mice: Protection by loop diuretics. Br J Exp Path. 1981;62(2):200.

7. Siddiqui N, Husain A, Lakshita CM Shamsher A, Moloy M, Parminder SB. Pharmacological and Pharmaceutical Profile of Valsartan: A Review. J Appl Pharm Sci. 2011;1(04):12-9.

8. Viberti GC, Wheeldon NM. Micro Albuminuria Reduction with VALsartan (MARVAL) Study Investigators: Microalbuminuria reduction with valsartan in patients with type 2 diabetes mellitus. A Blood Pressure-independent Effect: Circulation. 2002;106(6):672-8.

9. Gjorgjievska K, Zafirov D, Pavlova MJ, Cekovska S. Effects of Valsartan vs Amlodipin on renal function in salt loaded spontaneously hypertensive rats. Macedonian Pharm Bull. 2014;60(1):53-9.

10. Sasaki H, Saiki A, Endo K, Ban N, Yamaguchi T, Kawana H, et al. Protective effects of efonidipine, a T- and L-type calcium channel blocker, on renal function and arterial stiffness in type 2 diabetic patients with hypertension and nephropathy. J Atheroscler Thromb. 2009;16(5):568-75.

11. Ibrahim D. Evaluation of the potential nephroprotective and antimicrobial effect of Camellia sinensis leaves versus Hibiscus sabdariffa (in vivo and in vitro studies). Adv Pharmacol Sci. 2014;5. Article ID 389834.

12. Henry RJ. Determination of serum creatinine. In: Clinical. Chemistry principles and techniques. 2nd edition, Harper Row. 1974;525.

13. Hussein $\mathrm{H}$, Ibrahim $\mathrm{N}$. Impact of valsartan on some renal function parameters in hypertensive patients. IJPPS. 2019;4(3):65-7.

14. DeckW. Aminoglycosides and spectinomycin in Basic and Clinical Pharmacology, Katzung, Masters and Trevor, McGraw-Hill Education. 2018;821-31.

15. Clark et al. Protein synthesis inhibitors in Lippincott Illustrated Reviews Series. LWW; Seventh, North American edition. 2018;395-408.

16. Brunton L, Chabner B, Knollman B. Goodman and Gilman's; The Pharmacological Basis of Therapeutics. 12th ed. New York: McGraw Hill Medical Publishing Division. 2013.

17. Sari SP, Sartika SS, Rianti A. Side effects monitoring of aminoglycoside antibiotic in hospitalized patients. Int J App Pharm. 2018;10(Special Issue 1):291-3.

18. Abdelrahman RS. Protective effect of apocynin against gentamicin-induced nephrotoxicity in rats. HET. 2018;37(1):27-37.

19. Cheng J. Essential hypertension in "Applied therapeutics" Walters Kluwer. 2018; 133-61.

20. Flesch G, Muller PH, Lloyd P. Absolute bioavailability and pharmacokinetics of valsartan, an angiotenin II receptor antagonist in man. Eur J Clin Pharmcol. 1997:52(2):115-20

21. Delles C, Klingbeil AU, Schneider MP, Handrock P, Weidinger G, Schmieder RE. Direct Comparison of the Effects of Valsartan and Amlodipine on Renal Hemodynamics in Human Essential Hypertension. AJH. 2003;16(12):1030-5.

Article History: Submission Date : 16-03-2020; Revised Date : 27-03-2020; Acceptance Date : 07-04-2020.

Cite this article: Ibrahim DA, Al-mohamady A. Renoprotective Effects of Valsartan And Amlodipine in a Nephrotoxic Model of Experimental Animals. Int. J. Pharm. Investigation. 2020;10(2):208-10. 